\title{
Two domains of MyoD mediate transcriptional activation of genes in repressive chromatin: a mechanism for lineage determination in myogenesis
}

\author{
Anthony N. Gerber, ${ }^{1,2}$ Todd R. Klesert, ${ }^{1,2}$ Donald A. Bergstrom, ${ }^{1,2}$ and Stephen J. Tapscott ${ }^{1-4}$ \\ ${ }^{1}$ Divisions of Clinical Research and Molecular Medicine, Fred Hutchinson Cancer Research Center, Seattle, Washington \\ USA; Departments of ${ }^{2}$ Pathology and ${ }^{3}$ Neurology, University of Washington School of Medicine, Seattle, Washington USA
}

\begin{abstract}
Genetic studies have demonstrated that MyoD and Myf5 establish the skeletal muscle lineage, whereas myogenin mediates terminal differentiation, yet the molecular basis for this distinction is not understood. We show that MyoD can remodel chromatin at binding sites in muscle gene enhancers and activate transcription at previously silent loci. TGF- $\beta$, basic-FGF, and sodium butyrate blocked MyoD-mediated chromatin reorganization and the initiation of transcription. In contrast, TGF- $\beta$ and sodium butyrate did not block transcription when added after chromatin remodeling had occurred. MyoD and Myf- 5 were 10 -fold more efficient than myogenin at activating genes in regions of transcriptionally silent chromatin. Deletion mutagenesis of the MyoD protein demonstrated that the ability to activate endogenous genes depended on two regions: a region rich in cysteine and histidine residues between the acidic activation domain and the bHLH domain, and a second region in the carboxyl terminus of the protein. Neither region has been shown previously to regulate gene transcription and both have domains that are conserved in the Myf5 protein. Our results establish a mechanism for chromatin modeling in the skeletal muscle lineage and define domains of MyoD, independent of the activation domain, that participate in chromatin reorganization.
\end{abstract}

[Key Words: MyoD; Myf5; myogenin; myogenesis; chromatin; transcription]

Received December 3, 1996; revised version accepted January 3, 1997.

The myogenic family of basic helix-loop-helix (bHLH) proteins is composed of MyoD, Myf-5, myogenin, and MRF4 (Buckingham 1992; Edmondson and Olson 1993; Weintraub 1993). Each of these proteins recognizes a simple consensus sequence of CANNTG, termed an E box, present in the regulatory regions of many genes expressed in skeletal muscle (Blackwell and Weintraub 1990). In transfection assays, each of these proteins drives transcription of skeletal muscle reporters and can initiate expression of endogenous skeletal muscle genes, although some differences have been reported on specific enhancer elements (Asakura et al. 1993). Although these experiments suggested redundancy within the myogenic bHLH family, genetic studies demonstrated that MyoD and Myf- 5 act to establish the myogenic lineage, whereas myogenin mediates the expression of the terminal phenotype (Weintraub 1993; Rudnicki and Jaenisch 1995). Specifically, mice lacking both MyoD and Myf-5 do not develop any identifiable myoblasts (Rudnicki et al. 1993|. In contrast, mice lacking myogenin generate myoblasts, but show incomplete skeletal muscle differentia-

${ }^{4}$ Corresponding author.

E-MAIL stapscot@fred.fhcrc.org; FAX (206) 667-6524. tion, with fewer and smaller myotubes (Hasty et al. 1993; Nabeshima et al. 1993; Venuti et al. 1995). The differences between the myogenic genes that confer these specific attributes are unknown, but could be encoded by their regulatory regions, their protein sequences, or both.

Initiating gene transcription at a previously silent locus is one of the hallmarks of establishing a lineage. Chromatin repression and derepression of gene transcription in a developmental context has been studied extensively, particularly with regard to genes expressed in a tissue-restricted fashion (Weintraub 1985; Wolffe 1992; Felsenfeld et al. 1996). It is generally believed that regions of repressive chromatin act to silence certain lineage-specific genes, suppressing basal levels of transcription in nonexpressing lineages, and that developmentally regulated chromatin remodeling can increase the access of transcription factors to cis-acting regulatory regions of genes expressed in a particular lineage. For example, chromatin contributes to the repression of $\beta$-globin gene transcription in nonerythroid cells, whereas during erythrogenesis the chromatin at specific regulatory regions of the globin loci is remodeled into an active, derepressed state that permits greater access of tran- 
scription factors, manifested by the appearance of regions that have increased accessibility and sensitivity of the DNA to nucleases (Weintraub and Groudine 1976; Stalder et al. 1980; Reitman and Felsenfeld 1990). Whereas the generation of DNase hypersensitive sites at regulatory regions during development is well described, the mechanism for remodeling the chromatin in any lineage remains poorly understood. In one of the best-characterized examples, DNA-binding sites for the lineagerestricted transcription factors GATA-1 and NF-E2 have been shown to be necessary for the formation of hypersensitive sites in the $\beta$-globin loci (Philipsen et al. 1993; Stamatoyannopoulos et al. 1995; Boyes and Felsenfeld 1996) and binding of GATA-1 and NF-E4 can act to protect a $\beta$-globin gene template from chromatin-mediated transcriptional repression in vitro (Barton et al. 1993), yet the transcription factor characteristics required to mediate chromatin remodeling remain unclear.

There are some notable examples, however, that demonstrate the mechanisms by which transcription factors can activate gene expression within a repressive chromatin context. Work in a number of model systems has supported the basic notion that some transcription factors can recognize binding sites within a positioned nucleosomal array and can direct modifications of chromatin structure that allow gene activation to take place (Archer et al. 1992; Morse 1993). For instance, when yeast cells are cultured in high phosphate, positioned nucleosomes are present at the PHO5 gene. With phosphate starvation, the bHLH protein $\mathrm{Pho} 4$ binds to an intranucleosomal binding site. This causes a perturbation in nucleosome positioning that allows subsequent binding of Pho4 and other factors to sites that were occluded previously by the nucleosomal array, a process that is dependent on the Pho4 activation domain (Fascher et al. 1993; Svaren et al. 1994; Venter et al. 1994|. In vitro chromatin studies with the GAL4 transcription factor suggest a two-phase process for nucleosome displacement (Cote et al. 1994; Owen-Hughes et al. 1996). An initial disruption of the nucleosome is caused by the binding of the transcription factor, which recruits a multiprotein complex, such as the SWI/SNF complex, that completes nucleosome eviction in a manner dependent on ATP utilization. Similarly, the Drosophila GAGA factor has been shown to regulate chromatin structure, and in vitro assays suggest that it may function with a multiprotein nucleosome remodeling factor (NURF) that contains a protein related to the SWI2/ SNF2 protein (Granok et al. 1995; Tsukiyama and Wu 1995; Tsukiyama et al. 1995). Therefore, the general notion has emerged that sequence-specific transcription factors can recruit multiprotein nucleosome remodeling complexes to specific sites in the genome. Yet in a developmental context, very little is known regarding the relative abilities of transcription factors to initiate lineage-specific chromatin remodeling.

In the skeletal muscle lineage, the generation of muscle-specific chromatin alterations may be mediated by the MyoD family of transcription factors. Expression of MyoD in cultured cells activates both transfected re- porter genes driven by skeletal muscle promoters and the cognate endogenous genes (Weintraub et al. 1989). Binding sites for numerous other transcription factors are found in combination with $\mathrm{E}$ boxes in the regulatory regions of muscle genes and may contribute to initiating or maintaining transcription (Biben et al. 1994; Catala et al. 1995); however, no factors other than MyoD family members have been demonstrated clearly to be capable of activating endogenous muscle gene expression. For example, myocyte enhancer factor 2 (MEF2) sites are found in tandem with $\mathrm{E}$ boxes in the regulatory regions of many muscle genes (Li and Capetanaki 1994; Malik et al. 1995) and are critical for high-level, muscle-specific activation of reporter constructs in transient transfections and in transgenic mouse models (Adolph et al. 1993; Cheng et al. 1993). Whereas members of the MEF2 family activate transfected muscle-specific reporters and cooperate with MyoD family members in the activation of endogenous muscle genes (Black et al. 1995; Molkentin et al. 1995; Naidu et al. 1995), expression of MEF2 family members alone does not activate endogenous muscle gene expression (Molkentin et al. 1995), suggesting that MEF2 activity may be repressed by the native chromatin at transcriptionally silent skeletal muscle genes. Repressive chromatin may be the reason that many transcription factors enhance the expression of transfected reporter constructs but fail to activate expression of the endogenous copies of the target genes, because the chromatin packaging of transfected DNA does not recapitulate the native chromatin architecture (Reeves et al. 1985; Jeong and Stein 1994).

In this study we show that MyoD can remodel chromatin in the regulatory regions of skeletal muscle genes, an activity that is regulated by transforming growth factor (TGF- $\beta$ ) and basic fibroblast growth factor (bFGF). The ability to initiate endogenous gene transcription and remodel chromatin depended on two regions of $\mathrm{MyoD}$ that previously had no defined activity. These regions are separate from the activation and DNA-binding domains of MyoD, but have elements that are highly conserved in the Myf5 protein. Consistent with their genetically determined role in establishing the skeletal muscle lineage, MyoD and Myf5 can initiate transcription from genes in repressive chromatin with a 10-fold higher efficiency than myogenin. We conclude that MyoD and Myf5 contain specific domains that mediate chromatin remodeling, and suggest that the chromatin structure established by these lineage-determining proteins constrains the activity of other transcription factors, including myogenin, that mediate the expression of genes during differentiation. The demonstration that MyoD can remodel chromatin under the regulation of growth factors establishes a mechanism for lineage determination during myogenesis.

\section{Results}

$M y o D$ remodels chromatin at the myogenin locus

The proximal regulatory region of the myogenin gene has been characterized previously. A well-conserved 
180-bp fragment immediately upstream from the myogenin start site is sufficient to recapitulate myogenin expression patterns in transgenic mice /Cheng et al. 1993; Yee and Rigby 1993). This fragment contains two E boxes and an AT-rich region that can bind MEF2. Faithful recapitulation of the myogenin expression pattern during development requires the proximal E-box and the MEF2 site, indicating that MyoD and MEF2 family members regulate the expression of myogenin (Cheng et al. 1993). We have used 10T1/2-MyoD-ER (estrogen receptor) cells, a fibroblast cell line that expresses a fusion protein combining MyoD with the hormone-binding domain of the estrogen receptor, to analyze chromatin structure at the myogenin locus. 10T1/2-MyoD-ER cells can be induced to differentiate synchronously into skeletal muscle by the addition of $\beta$-estradiol (Hollenberg et al. 1993). In 10T1/2-MyoD-ER cells, myogenin transcription can be activated by MyoD in the presence of cycloheximide (see Fig. 5B, below), indicating that MyoD, in concert with ubiquitously expressed factors, is capable of directly activating myogenin transcription.

As an initial step in characterizing chromatin structure at the myogenin locus, DNase I was used to determine whether hypersensitive sites were present either before or after induction of transcription. Before induction of 10T1/2-MyoD-ER cells with estradiol, DNase I-hypersensitive sites were not detected between about -2000 and $+1000 \mathrm{bp}$ (Fig. 1A), a region that includes sequences that are sufficient for myogenin expression in transgenic mice. However, after $48 \mathrm{hr}$ of induction, two hypersensitive sites became evident (Fig. 1B, arrows). The proximal hypersensitive site mapped near the MyoD binding site at $-15 \mathrm{bp}$, whereas the more distal hypersensitive site mapped near the MEF2 site located at -75 bp (Fig 1C). This indicates that MyoD can induce myogenin transcription without a pre-existing hypersensitive site present in this region, and transcriptional activation is accompanied by regional chromatin reorganization.

We also analyzed nucleosome positioning around the myogenin promotor using micrococcal nuclease (MNase), which preferentially cleaves linker DNA. Identical banding patterns were observed with $10 \mathrm{~T} 1 / 2$ cells treated with estradiol (Fig. 2A) and with uninduced 10T1/2-MyoD-ER cells (not shown). Regularly spaced areas of protection of $-200 \mathrm{bp}$, consistent with the presence of a core nucleosome at each protected region, extended $>1 \mathrm{~kb}$ upstream from the start site (Fig. 2A). Clear regions of protection were centered at the start site and at $-200 \mathrm{bp}$, indicative of specifically positioned nucleosomes. The nucleosome positioned at the start site covers the proximal E box and the AT-rich region. In contrast, after the induction of myogenin transcription by estradiol treatment of 10T1/2-MyoD-ER cells, MNase digestion resulted in a pattern that was less distinct than in 10T1/2 cells that did not express the MyoD-ER construct, suggesting that the nucleosomes were not positioned as specifically following induction (Fig. 2, cf. A and $\mathrm{B}$ ). We conclude that MyoD induces a relaxation of nucleosome positioning at the myogenin promoter, po-
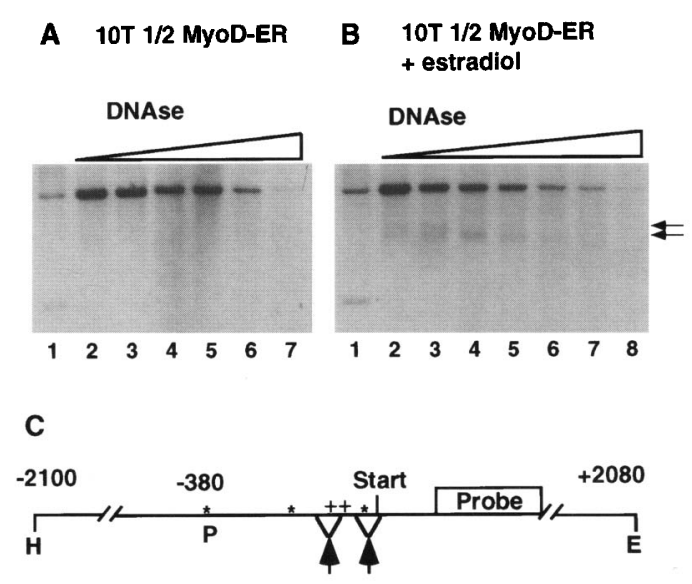

Figure 1. DNase hypersensitive sites develop at the myogenin locus after induction. Isolated nuclei from uninduced and induced 10T1/2 MyoD-ER cells were incubated with increasing concentrations of DNase I for $15 \mathrm{~min}$ at $37^{\circ} \mathrm{C}$. Following DNase I digestion, reactions were stopped, and the DNA was purified, digested with HindIII and EcoRI, and analyzed by Southern blot as indicated in the schematic. (A) No estradiol treatment: (Lane 1) No DNase; (lane 2) 0.2 units; (lane 3) 0.4 unit; (lane 4) 0.8 unit; (lane 5) 1.2 units; (lane 6) 1.6 units; (lane 7) 2.4 units. (B) Fortyeight hours of estradiol treatment. (Lane 1) No DNase; (lane 2) 0.2 unit; (lane 3) 0.4 unit; (lane 4) 0.6 unit; (lane 5) 0.8 unit; (lane 6) 1.2 units; (lane 7) 1.6 units; (lane 8 ) 2.4 units. The arrows indicate hypersensitive site bands. $(C)$ Approximate locations of probes, enzyme sites, and factor binding sites. (E) EcoRI $(\mathrm{H}) \mathrm{Hin}$ dIII; $\left(^{*}\right)$ E-box $;(++)$ MefII site. Arrows indicate approximate locations of HS sites, mapped using the blots in $A$ and $B$, and additional Southern analysis not shown.

tentially increasing access of factors to the proximal $\mathrm{E}$ box and the MEF2-binding site that are incorporated in a nucleosome in uninduced fibroblasts.

To test whether MyoD expression and the apparent relaxation of nucleosome phasing increased the access of factors to the myogenin promoter, we used restriction endonucleases to assess induction-associated changes in factor access at specific sites in myogenin chromatin, similar to restriction endonuclease access studies performed in other systems (McGhee et al. 1981; Loo and Rine 1994). Endonuclease access was assayed at eight sites ranging from a ClaI site at about $-6 \mathrm{~kb}$ to a Pst I site at about $+1100 \mathrm{bp}$. Figure $3 \mathrm{~A}$ shows Southern blots of restriction endonuclease access for several representative sites. For each experiment, the amount of DNA cleavage was determined when the enzyme was added to isolated nuclei (lanes marked $\mathrm{N}$ ) or to purified DNA (lanes marked P), and the ratio of the N/P band intensity is referred to as the percentage of enzyme access in nuclei (see Fig. 3; Materials and Methods). Following induction, enzyme access increases to $-50 \%$ in the proximal promoter region (Fig. 3B: -370 PvuII, -170 Pst , and -20 BanI) and in the coding region (Fig. 3B: +1040 BanI, +1070 Pst I), indicating a significant relaxation of chromatin structure in this region. This is consistent with the MNase results that showed disrupted nucleosome 
A
$10 \mathrm{~T} 1 / 2$ + estradiol
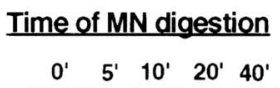
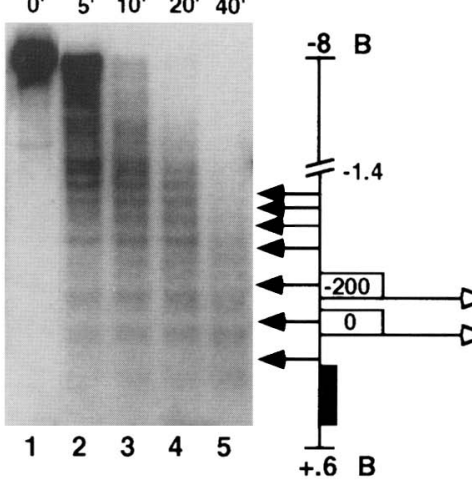

10T1/2-MyoD-ER + estradiol

Time of MN digestion

$\begin{array}{lllll}0^{\prime} & 5^{\prime} & 10^{\prime} & 20^{\prime} & 40^{\prime}\end{array}$

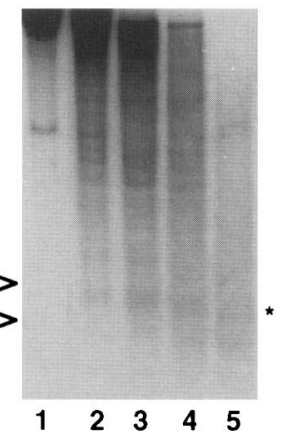

Figure 2. A phased nucleosomal array at the myogenin locus is modified with induction. Nuclei from $10 \mathrm{~T} 1 / 2$ cells $(A)$ and 10T1/2-MyoD-ER cells $(B)$ were isolated after $48 \mathrm{hr}$ induction with estradiol and incubated with $50 \mathrm{U} / \mathrm{ml}$ of MNase for increasing amounts of time as indicated. Following MNase treatment, DNA from each sample was purified, digested with BamHI, Southern blotted, and hybridized to the probe indicated in the schematic (solid rectangle). Regions of clear protection from MNase digestion, which represent locations of nucleosome cores, are indicated by solid arrows and are evident in $A$, lanes $2-5$. In $B$ the open arrowheads indicate positions 0 and $-200 \mathrm{bp}$, comparable to arrows in $A$. ( $\left.{ }^{\star}\right)$ Position of the proximal hypersensitive site seen in Fig. 1.

phasing in the proximal promoter region with induction, whereas increased enzyme access in the coding region is consistent with reports that the passage of the transcriptional machinery moves nucleosomes (Clark and Felsenfeld 1992). More modest increases in enzyme access were observed further upstream at the -1100 -bp NdeI site and the -1565-bp XbaI site, and no change in access was observed at the -6000 -bp ClaI site. Although a less extensive analysis was performed, similar results were obtained using NIH-3T3 cells, indicating that the chromatin remodeling is not specific to $10 \mathrm{~T} 1 / 2$ cells. Considered together, the DNase I, MNase, and restriction endonuclease analyses indicate that MyoD expression disrupted a phased nucleosome array at the myogenin promoter and relaxed chromatin structure modestly $>1$ $\mathrm{kb}$ upstream of the promoter.

Although MyoD can activate myogenin transcription directly (Hollenberg et al. 1993), it was not clear whether the changes in chromatin structure described above were mediated by MyoD directly, or, alternatively, whether factors induced by MyoD, such as MEF2, effected the changes in chromatin. To address this issue, we assayed endonuclease access to the myogenin promoter using nuclei isolated from cells induced with estradiol in the presence of cycloheximide. Cells were induced with estradiol for $10.5 \mathrm{hr}$, at which time myogenin mRNA levels were similar in cells treated with estradiol alone or with estradiol plus cycloheximide (Fig. 4B, cf. lanes 2 and
4), and enzyme access was determined at the $-170-\mathrm{bp}$ PstI site and the +1080 -bp PstI site (Fig. 4A). In the absence of induction, cycloheximide increased the restriction enzyme access approximately twofold (Fig. 4A, probe $\mathrm{A}$, cf. lanes 1 and 5), and there was an additional twofold increase in access following induction in the presence of cycloheximide (cf. lanes 5 and 7). Although this twofold increase in access at the -170 bp PstI site following induction in cycloheximide was notably smaller than the 6- or 10-fold increase at the -170-bp PstI site seen without cycloheximide (Fig. 4A, probe A, cf. lanes 1 and 3), a two- to threefold increase in enzyme access following induction in cycloheximide was consistent among several experiments (see, e.g., Fig. 4C, cf. lanes 1 and 3). Access to the -370 -bp PvuII and the -20 bp BanI sites showed a similar two- to threefold increase with induction in cycloheximide (data not shown), whereas in the coding region induction increased enzyme access at the +1070-bp PstI site to similar levels with and without cycloheximide treatment (Fig. 4A, probe $B$, cf. lanes 3 and 7). Therefore, we conclude that MyoD initiates chromatin reorganization directly and that newly synthesized factors cooperate with MyoD to achieve complete remodeling of the chromatin structure at the myogenin promoter.

We next tested the effect of depleting ATP on the induction of chromatin reorganization by using the metabolic poisons sodium azide and deoxyglucose. These agents deplete cellular ATP (Lorico et al. 1995) and prevented the generation of detectable myogenin transcripts after estradiol induction (Fig. 4B, lane 6), presumably by inhibiting RNA polymerase II (Pol II), which has been shown to require ATP both for transcription initiation and elongation (Jiang et al. 1996). Treatment with sodium azide and deoxyglucose did not, however, prevent an increase of enzyme accessibility to the -170 -bp PstI site in the promoter (Fig. 4C, cf. lanes 5 and 7), similar to the results seen with cycloheximide (Fig. 4C, cf. lanes 3 and 7). Thus, MyoD can initiate chromatin reorganization at the myogenin promoter in the absence of detectable myogenin transcription and when cellular ATP is depleted.

\section{MyoD alters chromatin structure at distal enhancer elements of other muscle genes}

To determine whether MyoD alters chromatin structure at other skeletal muscle genes, we measured the accessibility of restriction endonucleases at sites adjacent to the MyoD-binding sites in the enhancer regions of two other genes regulated by $\mathrm{MyoD}$, muscle creatine kinase $(M C K)$ and myoD (Jaynes et al. 1988; Tapscott et al. 1992). Similar to myogenin, enzyme access increased in the regulatory regions of these genes following $48 \mathrm{hr}$ of induction (Fig. 5A-C), indicating that chromatin alterations occur with induction at the $M C K$ and myoD loci. The regulatory regions of myoD and $M C K$ that were analyzed in these experiments are 5.2 and $1.2 \mathrm{~kb}$ upstream of the respective transcription start sites, demonstrating 


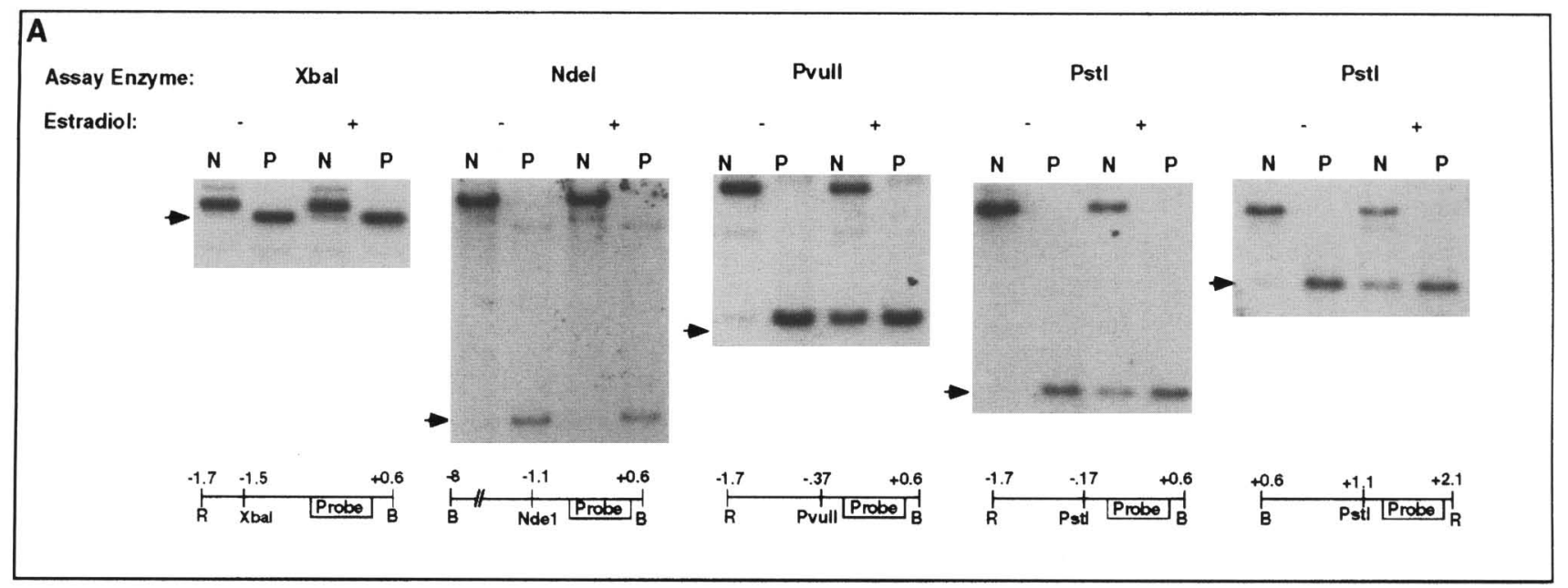

$\mathrm{B}$ No induction
Induction

Figure 3. Restriction enzyme access to the myogenin locus increases with induction. $(A)$ Southern blot analysis assessing changes in enzyme activity at the myogenin locus with induction in $10 \mathrm{~T} 1 / 2-\mathrm{MyoD}-\mathrm{ER}$ cells. Nuclei were isolated from uninduced cells (estradiol-) and cells induced for $48 \mathrm{hr}$ (estradiol + ). Nuclei were incubated at $37^{\circ} \mathrm{C}$ for 30 min with 40 units of a given restriction endonuclease (assay enzyme). Reactions were stopped and the DNA was purified and digested to completion with flanking enzymes as depicted in the schematics below each blot. To express the accessibility of the site in isolated nuclei relative to purified DNA as a percentage, half the sample was digested further to completion with the assay enzyme. $(\mathbf{P})$ Samples exposed to the assay enzyme as purified DNA $(\mathrm{N})$ samples exposed to the assay enzyme only as isolated nuclei. Bands generated by cleavage with the assay enzyme are indicated by arrows. The percent accessibility of each site was determined as the density ratio of the arrowed bands for each nuclei/purified sample pair using a Molecular Dynamics PhosphorImager. $(B)$ Schematic showing percent accessibility to sites in the myogenin locus with and without induction, calculated using the procedure described above. Results shown are representative of the typical experiment.

that chromatin alterations can be induced at sites relatively distant from promoter elements.

Several control experiments were performed to demonstrate that chromatin changes with induction were attributable to MyoD activity and were specific to skeletal muscle genes. Access to a BanI site in the locus control region (LCR) of the $\beta$-globin gene, which is not transcribed in skeletal muscle, did not increase with induction in 10T1/2-MyoD-ER cells, and estradiol treatment of $10 \mathrm{~T} 1 / 2$ cells that lack the MyoD-ER protein did not change the access of $B a n I$ to the myogenin promoter (Fig. 5D,E).

Previous work has shown that both MyoD and E proteins can bind to the $\mathrm{E}$ boxes in the enhancer of the immunoglobulin heavy chain $(\mathrm{Ig} H)$ gene and regulate transcription of $I g H$ reporter constructs in transfection assays (Weintraub et al. 1994). Because MyoD can interact functionally with these $\mathrm{E}$ boxes, yet the $\mathrm{IgH}$ gene is not transcribed in skeletal muscle, we wanted to determine whether MyoD expression would alter enzyme access at this enhancer. The enhancer contains three functional $\mathrm{E}$ boxes, one of which, E2, is identical to the $\mathrm{E}$ box in the myogenin promoter at $-370 \mathrm{bp}$. In contrast to the marked increase in PstI access to a site adjacent to the $\mathrm{E}$ box in the myogenin promoter (Fig. 3), access of PstI to a site directly adjacent to the E2 E box remained low following induction of $10 \mathrm{Tl} / 2-\mathrm{MyoD}-\mathrm{ER}$ cells with estradiol (Fig. 5F). Together, the data shown in Figure 5 indicate that MyoD relaxed chromatin in the region of MyoD-binding sites specifically at genes that are expressed in skeletal muscle.

\section{Growth factors prevent MyoD-mediated chromatin relaxation}

The activity of MyoD as a transcription factor can be inhibited by a number of agents in cell culture, potentially reflecting mechanisms that modulate the activity of $\mathrm{MyoD}$ in vivo. For example, sodium butyrate, which inhibits histone deacetylase, inhibits MyoD activity and myogenesis in cell culture (Johnston et al. 1992). Likewise, the growth factors TGF- $\beta$ and bFGF, which are present in the developing limb bud and somite, can inhibit the activity of both MyoD and myogenin in cell culture (Hannon et al. 1992; Li et al. 1992; Martin et al. 1992). Furthermore, TGF- $\beta$ has been shown recently to 
A
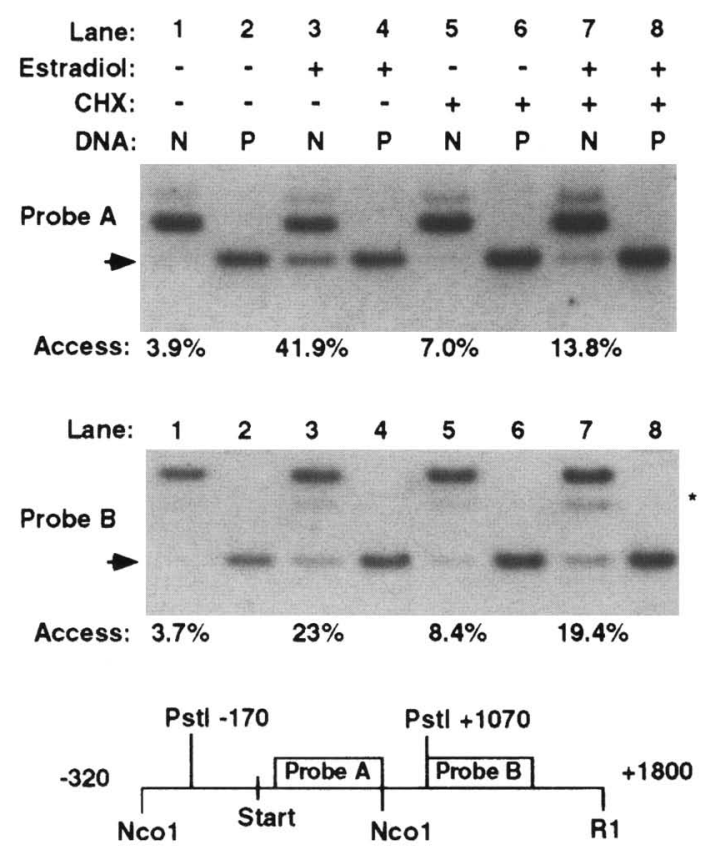

B

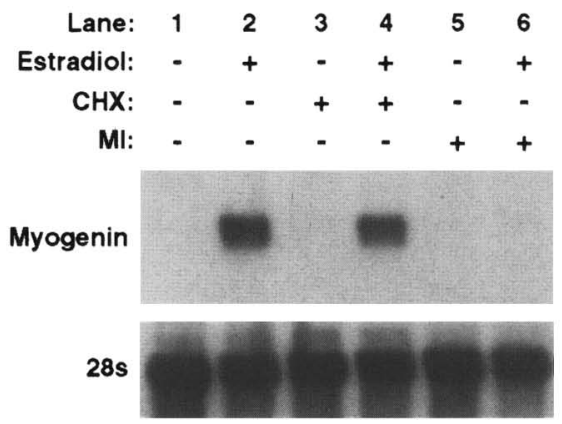

C

$\begin{array}{rrrrrrrrr}\text { Lane: } & 1 & 2 & 3 & 4 & 5 & 6 & 7 & 8 \\ \text { Estradiol: } & - & - & + & + & - & - & + & + \\ \text { CHX: } & + & + & + & + & - & - & - & - \\ \text { MI: } & - & - & - & - & + & + & + & + \\ \text { DNA: } & \text { N } & \text { P } & \text { N } & \text { P } & \text { N } & \text { P } & \text { N } & \text { P }\end{array}$

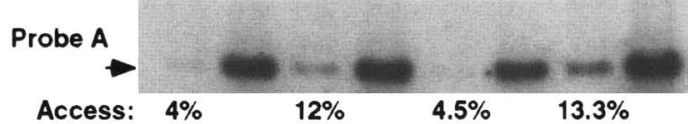

Figure 4. MyoD induces changes in chromatin structure at the myogenin promoter when protein synthesis or ATP production are blocked. (A) Southern blot of myogenin locus showing enzyme access to the PstI site in the promoter (probe 1) or the coding region (probe 2) of uninduced (estradiol-) and induced (estradiol + ) cells treated with and without cycloheximide (CHX) (50 $\mu \mathrm{g} / \mathrm{ml}$.) Nuclei were isolated and percent access to the PstI site was determined as described in Fig. 3 and in Materials and Methods, using the flanking enzymes $\mathrm{NcoI}$ and EcoRI (schematic). The same blot was probed sequentially with probe 1 and $2 .\left(^{\star}\right)$ Residual signal from the first probe $_{i}(N)$ nuclei $;(P)$ purified. $(B)$ Northern analysis using RNA from uninduced and induced cells treated with $\mathrm{CHX}$ or the metabolic inhibitors (MI), sodium azide $(.1 \%)$, and deoxyglucose $(5 \mathrm{~mm})$ as indicated. $(C)$ Southern blot showing enzyme access to the PstI site in the myogenin promoter of cells treated as indicated. For $A-C$, cells were induced for $10.5 \mathrm{hr}$.

modulate the interaction between a domain of the CTF-I transcription factor and histone $\mathrm{H} 3$ (Alevizopoulos et al. 1995). To determine whether these agents could prevent MyoD-mediated relaxation of chromatin structure, $10 \mathrm{~T} 1 / 2-\mathrm{MyoD}-\mathrm{ER}$ cells were cultured in the presence of sodium butyrate, bFGF, or TGF- $\beta$, and enzyme access to the BanI site in the myogenin promoter was assessed after $24 \mathrm{hr}$ of estradiol induction (Fig. 6A). All three agents inhibited MyoD-induced increases in enzyme access to this site (cf. lanes 2, 4, 6, and 8). The accumulation of myogenin message also was inhibited by the addition of these agents at the time of induction (Fig. 6C, lanes 2,7; data not shown). Therefore, TGF- $\beta$, bFGF, and sodium butyrate inhibit the ability of MyoD to induce chromatin remodeling at the myogenin locus and block the initiation of myogenin transcription.

To test whether these agents were able to block transcription at the myogenin locus when an active chromatin conformation and transcription complex was already established, we assayed myogenin mRNA levels and enzyme access in 10T1/2-MyoD-ER cells that had been induced in differentiation medium supplemented with estradiol for $24 \mathrm{hr}$, followed by growth for an additional $24 \mathrm{hr}$ in differentiation medium alone, or differentiation medium supplemented with either sodium butyrate or TGF- $\beta$ (Fig. 6B,C). With estradiol treatment alone, high levels of myogenin mRNA were present at $24 \mathrm{hr}$ (Fig. 6C, lanes 1,6 ) and further increased at $48 \mathrm{hr}$ (Fig. 6C, lanes 3,8). Myogenin expression between 24 and $48 \mathrm{hr}$ in the absence of continued estradiol treatment reflects a stable activation state that is likely maintained by autoregulation. TGF- $\beta$ and sodium butyrate added at the time of induction suppressed mRNA accumulation (lanes 2,7), whereas cells induced with estradiol for $24 \mathrm{hr}$ and then exposed to TGF- $\beta$ or sodium butyrate for $24 \mathrm{hr}$ maintained the level of myogenin RNA present at $24 \mathrm{hr}$ of induction (lanes 4,9). Because the half-life of myogenin mRNA is $<8 \mathrm{hr}$ (data not shown), the mRNA levels after $24 \mathrm{hr}$ of treatment with TGF- $\beta$ or sodium butyrate were not simply attributable to message stability, and we conclude that myogenin transcription persists in the presence of either inhibitor. Furthermore, the chromatin conformation at the myogenin locus remained accessible to restriction enzymes in cells treated with TGF- $\beta$ or sodium butyrate following $24 \mathrm{hr}$ of induction (Fig. 6B, lanes 3,5$)$.

It is unlikely that induction makes the cells unresponsive to these agents, because the expression of muscle genes that had not been fully activated at $24 \mathrm{hr}$ of induction were inhibited by subsequent addition of TGF- $\beta$ or sodium butyrate. For example, Figure $6 \mathrm{C}$ shows that myosin heavy chain $(\mathrm{MyoHC})$ mRNA increased dramati- 
Figure 5. Chromatin structure is altered in the regulatory regions of several muscle genes with induction. $(A-D)$ Isolated nuclei from uninduced (lane 1-estradiol) and induced (lane 2 +estradiol) $10 T 1 / 2$ MyoD-ER cells were incubated with 40 units of BanI enzyme for $30 \mathrm{~min}$. Reactions were stopped and Southern blotted as indicated in the schematics, which show the approximate locations of probes, selected enzyme sites, and E boxes within each regulatory region. Lane 3 (naked) of each blot is purified DNA-digested to completion with BanI and flanking enzymes. (E) Similar to Fig. $4 \mathrm{~A}$, except samples were isolated from $10 \mathrm{~T} 1 / 2$ cells not expressing the myoD-ER construct. (F Similar to above, except PstI access to a site in the $\operatorname{IgH}$ enhancer was assessed. (Ap) ApaI; (B) BamHI; (H) HindIII; (N) NcoI; (P) PvuII; (Rl) EcoRI; (X) XhoI: (*) E-box.

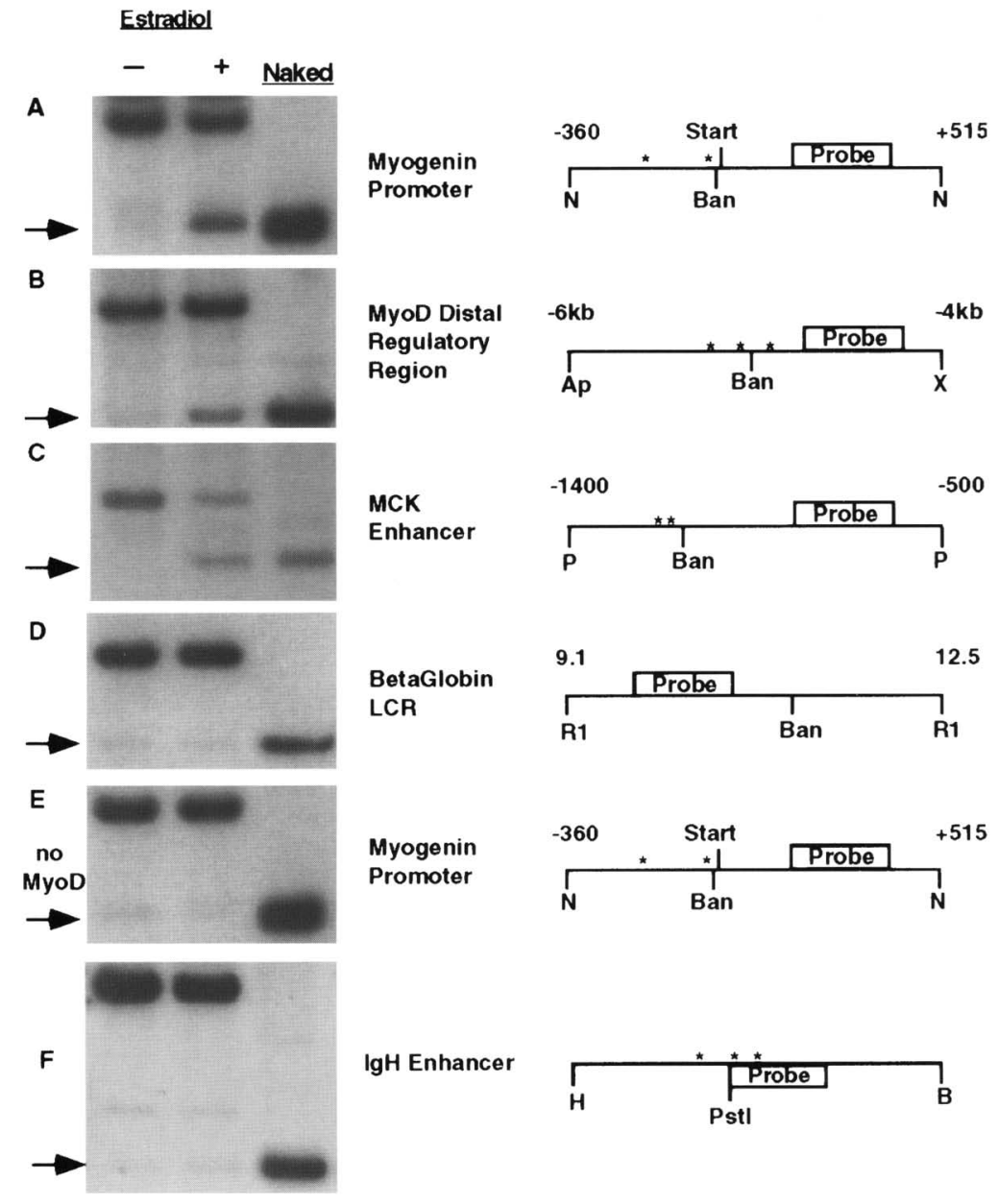

cally between 24 and $48 \mathrm{hr}$ (cf. lanes 1 and 3), but addition of TGF- $\beta$ at $24 \mathrm{hr}$ blocked the increase in mRNA levels substantially (cf. lanes 3 and 4). Therefore, the ability of TGF- $\beta$ and sodium butyrate to inhibit transcription depended on whether an active chromatin structure and transcription complex had been established at the target gene. This could represent a mechanism for differential regulation of gene transcription by these agents.

\section{MyoD is less sensitive to chromatin repression than myogenin}

Although there is functional redundancy within the MyoD family (Wang et al. 1996), MyoD and Myf-5 act preferentially in myoblast specification, whereas myogenin and MRF4 drive terminal differentiation $(\mathrm{Na}$ beshima et al. 1993; Venter et al. 1994; Venuti et al. 1995). To determine whether MyoD and myogenin had equal abilities to activate transcription of genes in inactive chromatin, we analyzed the relative abilities of MyoD and myogenin to activate endogenous muscle genes. Initially, we characterized activation of endogenous desmin and MyoHC genes in 3T3 cells transfected with expression plasmids containing the enhancer of the murine sarcoma virus driving MyoD or myogenin, pEMSV-MyoD, or pEMSV-myogenin. We used 3T3 cells because the endogenous myoD gene is not autoactivated following transfection of myoD expression vectors (Thayer et al. 1989); however, similar results were obtained using $10 \mathrm{~T} 1 / 2$ cells. Cells were also transfected with pCMV-lacZ to control for transfection efficiency and p4RTK-CAT, which consists of four multimerized E boxes driving chloramphenicol acetyltransferase (CAT) (Weintraub et al. 1991). The simultaneous assay of transcription factor activity on a transfected reporter and on an endogenous gene was used to determine the relative efficiency of the factor to activate a gene that is in a nontranscribed region of genomic chromatin. Following overnight calcium phosphate transfection, cells were placed in differentiation medium for $24 \mathrm{hr}$ and then double-stained with antibodies to MyoHC and CAT or MyoHC and desmin. MyoD and myogenin activated transcription from the p4RTK-CAT plasmid with similar efficiencies, based on counts of CAT-positive cells in equal areas of each dish and quantitative CAT assays from sister plates (Table 1). MyoD activated transcription of the endogenous $\mathrm{MyoHC}$ and desmin genes at a frequency equal to its activation of p4RTK-CAT, with a 
A

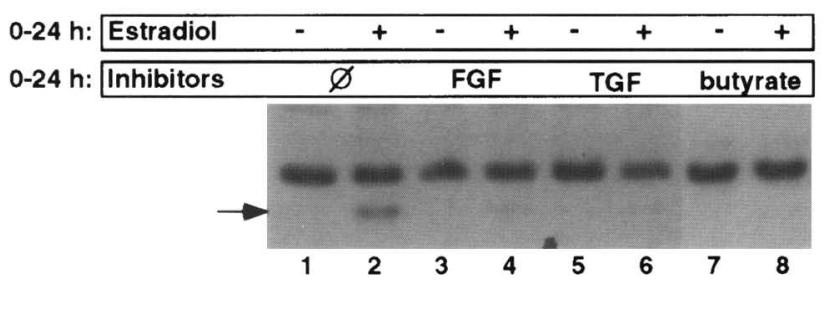

B

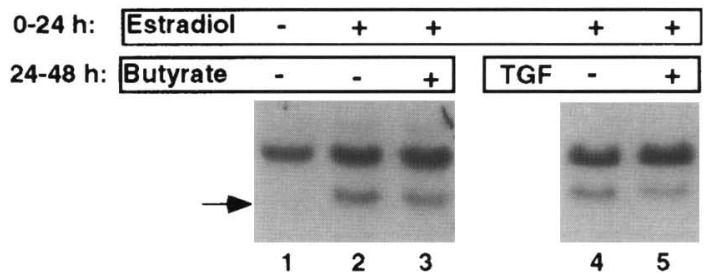

C

\begin{tabular}{|c|c|c|c|c|c|c|c|c|c|c|c|}
\hline $0-24 \mathrm{~h}:$ & Estradiol & + & + & + & + & & - & + & + & + & + \\
\hline $0-24 \mathrm{h:}$ & TGF & - & + & - & - & Butyrate & - & - & + & - & - \\
\hline 24-48 $\mathrm{h}:$ & TGF & & & - & + & Butyrate & & & & - & + \\
\hline
\end{tabular}

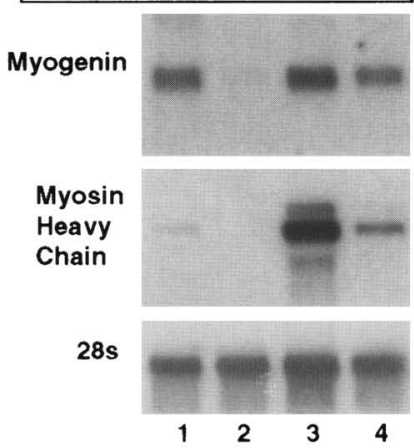

Myogenin

$28 \mathrm{~s}$

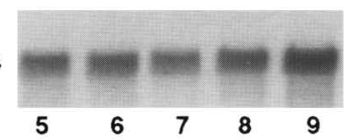

Figure 6. Effects of growth factors and sodium butyrate on chromatin structure and muscle gene expression. $(A)$ Southern analysis of access to the BanI site in the myogenin promoter with and without induction, and with and without basic FGF (25 ng/ml), TGF- $\beta$ $(0.2 \mathrm{nM})$, or sodium butyrate $(5 \mathrm{~mm})$ treatment as indicated. $(B)$ Southern analysis of access to the BanI site at the myogenin promoter with TGF and butyrate treatment following $24 \mathrm{hr}$ of induction. $(C)$ Northern analysis of myogenin and myosin heavy chain expression with TGF and butyrate treatment. Agents were added at either the time of induction or following $24 \mathrm{hr}$ of induction as indicated.

ratio of MyoHC/CAT-positive cells of 0.9 and a desmin/ CAT ratio of 1.03. In contrast, myogenin showed many fewer MyoHC- and desmin-positive cells, with a $\mathrm{MyoHC} / \mathrm{CAT}$ ratio of 0.08 . The overall transfection efficiencies were similar based on staining of duplicate plates for MyoD, myogenin, or LacZ (data not shown). Northern analysis using a probe to MyoHC confirmed that the number of cells expressing each protein reflected levels of transcript present in the cell population (data not shown), supporting our interpretation that the

Table 1. Activation of endogenous muscle genes compared to transfected reporters by MyoD and myogenin

\begin{tabular}{|c|c|c|c|c|c|c|c|c|c|}
\hline \multirow{4}{*}{$\begin{array}{l}\text { Experiment } 1^{\mathrm{a}} \\
\text { MyoD } \\
\text { Myogenin } \\
\text { Experiment } 2^{\mathrm{b}}\end{array}$} & MyoHC & \multicolumn{2}{|c|}{ 4RTK-CAT } & \multicolumn{2}{|c|}{$\begin{array}{c}\text { Ratio } \\
\text { (MyoHC/4RTK-CAT) }\end{array}$} & \multicolumn{2}{|c|}{ Desmin } & \multicolumn{2}{|c|}{$\begin{array}{c}\text { Ratio } \\
(\text { desmin/4RTK-CAT })\end{array}$} \\
\hline & 86 & & & & 90 & & & 1.0 & \\
\hline & 12 & 151 & $5 \times 1$ & & 08 & & & 0.0 & \\
\hline & MyoHC & 4RTK-CAT & Ratio & Desmin & Des-CAT & Ratio & MCK & MCK-CAT & Ratio \\
\hline MyoD & 61 & $52(7.4 \times)$ & 1.2 & 70 & $33(8.8 \times)$ & 2.12 & 6 & 29 & 0.21 \\
\hline Myogenin & 10 & $114(6.8 \times)$ & 0.09 & 6 & $28(8.9 x)$ & 0.21 & 0 & 21 & 0 \\
\hline
\end{tabular}

${ }^{a}$ Cells were cotransfected overnight with either pEMSV-MyoD or pEMSV-myogenin and p4RTK-CAT, and prepared for immunohistochemistry after $24 \mathrm{hr}$ in differentiation medium. The integers are counts of cells staining positive with antibody to the indicated muscle marker or to CAT within a standard area of a dish. Totals for MyoHC and CAT reflect cells within the same area on the same dish, whereas for desmin, equivalent areas of sister dishes were counted. The ratio was calculated using the cell count totals. Numbers in parentheses reflect fold activation attained in a quantitative CAT assay using sister dishes, relative to the parent EMSV vector. ${ }^{b}$ Cells were cotransfected with either pEMSV-MyoD or pEMSV-myogenin, and either p4RTK-CAT or pDesmin-CAT or p3300MCKCAT. As in experiment 1, integers are counts of cells staining positive as indicated within a standard area of each dish, and parenthetical numbers reflect fold activation in quantitative CAT assays. For MyoHC and CAT, the same areas on the same dish were counted, whereas for desmin vs. CAT and MCK vs. CAT, equivalent areas on sister dishes were counted. The muscle marker to CAT ratios were calculated using the cell count totals. 
indirect immunofluorescent assay of protein expression represented relative gene activity.

Therefore, relative to their activity on p4RTK-CAT, MyoD was more efficient than myogenin in activating the endogenous desmin and myoHC genes, which may reflect differences in the abilities of $\mathrm{MyoD}$ and myogenin to activate genes in an inactive region of chromatin. Alternatively, the $\mathrm{MyoHC}$ and desmin genes may be activated preferentially by MyoD as a result of binding-site specificity for MyoD or interaction with other transcription factors that bind the enhancer, as has been described previously for $\mathrm{E}$ boxes in the myosin light chain regulatory region (Asakura et al. 1993). To address the latter possibility, we determined the relative abilities of $\mathrm{MyoD}$ and myogenin to activate transcription of the endog. enous desmin gene compared with a transfected p1.7des-CAT reporter gene, and the endogenous $M C K$ gene compared with a transfected p3300MCK-CAT reporter gene. The desmin CAT reporter contains $1.7 \mathrm{~kb}$ of sequence 5-' of the transcription start site (Pieper et al. 1987), and the MCK-CAT has $3.3 \mathrm{~kb}$ of upstream sequence (Jaynes et al. 1988). Cultured 3T3 cells were transfected in triplicate with the CAT reporter plasmid and either pEMSV-MyoD or pEMSV-myogenin. Plates were immunostained with a mouse monoclonal antibody to MyoHC and a rabbit polyclonal antibody to either CAT, desmin, or MCK proteins and positive cells counted in a standard area (Table 1). Activation of the p1.7des-CAT and the p3300MCK-CAT reporters was similar with either pEMSV-myoD or pEMSV-myogenin transfection; yet many more desmin- and MCK-staining cells were detected in the plates transfected with pEMSVmyoD than in the plates transfected with pEMSV-myogenin, similar to results obtained comparing activation of p4RTK-CAT with endogenous MyoHC. Therefore, MyoD and myogenin have comparable abilities to enhance transcription of transfected templates, but MyoD activates endogenous muscle genes more efficiently than myogenin.

We also compared the relative ability of Myf5 to activate transcription of endogenous genes. We transfected $3 \mathrm{~T} 3$ cells with the p4RTK-CAT reporter and the pEMSV vector driving myoD, myogenin, or Myf5. The ratio of MyoHC-positive/CAT-positive cells, or myogenin-positive/CAT-positive cells, was used to calculate the relative activity of each transcription factor on endogenous genes, expressed as the percentage of activity relative to MyoD (Table 2). Myf5 was comparable to MyoD in its ability to induce transcription of an endogenous gene relative to its activity on the transfected reporter construct, and both MyoD and Myf5 were $\sim 10$-fold more efficient on endogenous genes than myogenin.

Efficient activation of endogenous genes depends on two regions of MyoD that are separate from the acidic activation and bHLH domains

A series of deletion mutations of the MyoD protein (Tapscott et al. 1988) were used to determine whether a domain of MyoD conferred its ability to activate endog-
Table 2. Two domains of $M y o D$ mediate activation of endogenous genes

\begin{tabular}{|c|c|c|}
\hline Plasmid & $\begin{array}{c}\text { MyoHC/CAT } \\
\mid \% \text { MyoD activity }\left.\right|^{a}\end{array}$ & $\begin{array}{c}\text { Myogenin/CAT } \\
(\% \text { MyoD activity })^{a}\end{array}$ \\
\hline MyoD & 100 & 100 \\
\hline Myogenin & 7 & N.D. \\
\hline Myf-5 & 75 & 86 \\
\hline $\operatorname{MyoD}(\Delta 3-51)$ & 64 & 215 \\
\hline $\operatorname{MyoD}(\Delta 63-99)$ & 30 & 0.5 \\
\hline $\operatorname{MyoD}(\Delta 167-318)$ & 44 & 19 \\
\hline $\operatorname{MyoD}(\Delta 270-318)$ & 129 & 218 \\
\hline $\operatorname{MyoD}(\Delta 170-209)$ & N.D. & 733 \\
\hline $\operatorname{MyoD}(\Delta 218-269)$ & N.D. & 22 \\
\hline
\end{tabular}

3T3 Cells were cotransfected overnight with the indicated expression plasmid and p4RTK-CAT, and prepared for immunohistochemistry after $24 \mathrm{hr}$ in differentiation medium. Cells were stained with antibodies to $\mathrm{MyoHC}$ (monoclonal) and CAT (polyclonal), or myogenin (monoclonal) and CAT. The number of cells staining positive for the indicated muscle marker or CAT in standard areas of each dish was used to determine $\mathrm{MyoHC} / \mathrm{CAT}$ and myogenin/CAT ratios for each plasmid. The ratio obtained with $\mathrm{MyoD}$ transfection for each experiment was set at $100 \%$, and the other percentages were normalized accordingly. Results from independent experiments were averaged. ${ }^{a}$ Not determined.

enous genes. Following transfection of $3 \mathrm{~T} 3$ cells with p4RTK-CAT and various MyoD mutants in the pEMSV expression vector, we assessed the relative efficiency of activating $\mathrm{MyOHC}$ or the endogenous myogenin gene for each deletion mutant of MyoD (Table 2). Deletion of the amino-terminal acidic activation domain [MyoD( $\Delta 3-51)]$ and the carboxyl terminus [MyoD( $\Delta 270-318)]$ did not impair the ability of the mutant $\mathrm{MyoD}$ to activate expression of the endogenous myogenin gene. In contrast, deletion of residues 63-99 [MyoD( $\Delta 63-99)]$ decreased the activation of the endogenous myogenin gene nearly 100 fold relative to the number of CAT-positive cells. A second region between residues 218 and 269 also contributed to activating the endogenous myogenin gene, because $\mathrm{MyoD}(\Delta 218-269)$ has a lower activity than either wild-type $\mathrm{MyoD}$ or $\mathrm{MyoD}(\Delta 270-318)]$. A similar trend in the activity of the MyoD deletions was observed for the ratio of MyoHC-positive/CAT-positive cells (Table 2), but the differences between constructs were not as large.

It is interesting that deletion of amino acids 170-209 apparently increases the activity of MyoD on the endogenous myogenin gene. This increased activity may depend on the presence of amino acids 218-269, because the termination mutant $\mathrm{MyoD}(\Delta 167-318)$ has an activity similar to $M y o D(\Delta 218-269)$, suggesting that the region between 170 and 209 may negatively regulate the activity of the region between 218 and 269 .

Quantitative assays of reporter activity were also performed for each construct by use of a p4RTK-luciferease reporter (Fig. 7). Whereas $\mathrm{MyoD}(\Delta 63-99)$ and $\mathrm{MyoD}$ $(\Delta 218-269)$ were slightly less active than the wild-type MyoD $160 \%$ and $70 \%$ of the activity of MyoD, respectively), they were both more than twice as active as 


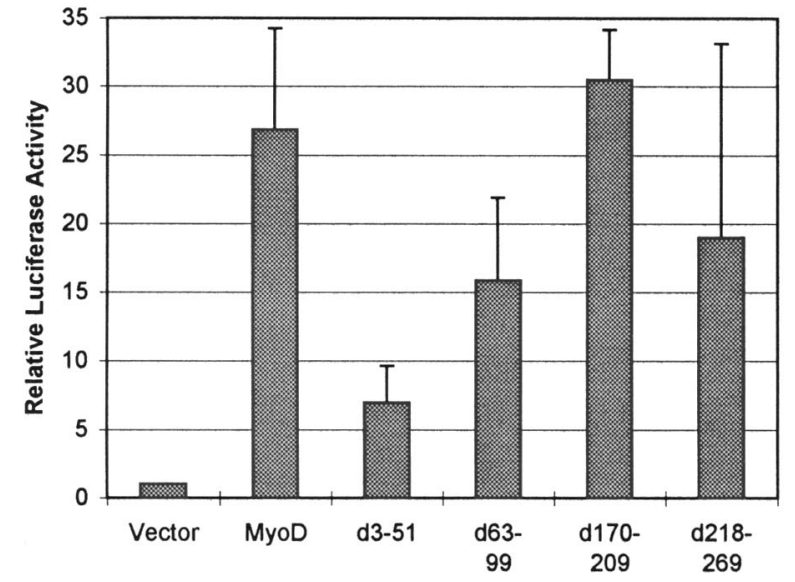

Figure 7. Activity of $\mathrm{MyoD}$ deletion mutants on transiently transfected p4RTK-luciferase. $3 \mathrm{~T} 3$ cells were transfected with the indicated expression vector following the protocol described in Table 2, using a luciferase reporter instead of a CAT reporter. Transfections were performed in triplicate and numbers represent the luciferase activity relative to vector alone. A cotransfected $p C M V-l a c Z$ vector was used to normalize values for transfection efficiency.

the $\operatorname{MyoD}(\Delta 3-51)$, which efficiently induced expression of the endogenous myogenin gene. Because saturation of the activity of wild-type MyoD could obscure a greater difference between the mutant proteins, we also performed a titration of wild-type $\mathrm{MyoD}$ and $\mathrm{MyoD}(\Delta 63-99)$ comparing activity on a transfected p4RTK-luciferase reporter and the endogenous myogenin gene with similar results (data not shown). Therefore, the ability of the deletion mutants to activate endogenous genes does not correlate with their transcriptional activity on a transfected reporter, and we conclude that specific regions of MyoD increase the efficiency of initiating transcription of endogenous genes.

The region of MyoD between amino acids 63 and 99 is necessary for chromatin remodeling

The region between amino acids 63 and 99 is rich in cysteine and histidine residues, and has been designated the $\mathrm{C} / \mathrm{H}$ region (Tapscott et al. 1988; Weintraub et al. 1991). Because deletion of this region had the largest effect on the activation of endogenous genes, we next tested whether deletion of this region influenced chromatin remodeling. The role of the amino-terminal activation domain was also evaluated, because transcription factor activation domains have been implicated previously in chromatin remodeling (Svaren et al. 1994). We

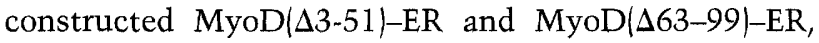
analogous to MyoD-ER, and analyzed PstI access at the myogenin promoter in $10 \mathrm{~T} 1 / 2$ cells. Following $10.5 \mathrm{hr}$ of induction, enzyme access to the -170 -bp Pst site in the myogenin promoter was increased only weakly in 10T1/ 2-MyoD( $(463-99)-E R$ cells (Fig. 8, lanes 5-8), whereas cells expressing MyoD( $\Delta 3-51)$-ER (Fig. 8A, lanes 1-4) or
MyoD-ER (see Fig. 4) exhibited marked increases in access to this site. Thus, deletion of the $\mathrm{C} / \mathrm{H}$ region impaired the ability of MyoD to remodel chromatin. In contrast to its weak activity on chromatin remodeling, MyoD( $\Delta 63-99)$-ER showed activity similar to that of MyoD-ER and MyoD( $\Delta 3-51)$-ER on transfected p4RTKCAT reporters (Fig. $8 \mathrm{~B}$; data not shown). The relatively higher activity of the $M y o D(\Delta 3-51)$-ER in this assay, compared with that shown in Figure 7 , most likely reflects the efficient activation of endogenous myogenin that contributes to reporter activation, although the ER domain may also affect its activity (see Discussion). We conclude that the $\mathrm{C} / \mathrm{H}$ region allows $\mathrm{MyoD}$ to access binding sites efficiently in repressed chromatin and initiate chromatin remodeling.

\section{Discussion}

This study has shown that MyoD remodels chromatin at target genes. Chromatin relaxation and initiation of gene transcription were induced by MyoD at the myogenin locus in the absence of protein synthesis, indicating that

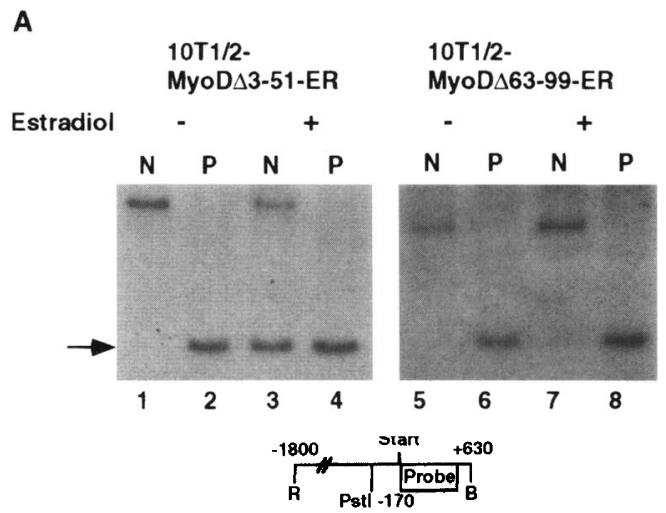

B

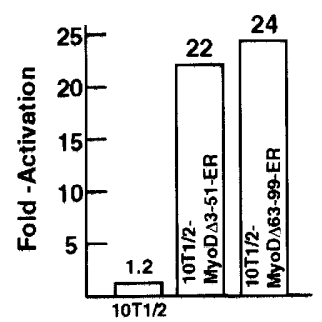

Figure 8. Chromatin remodeling is impaired with deletion of the $\mathrm{C} / \mathrm{H}$ region, but not the activation domain. 10T1/2$\operatorname{MyoD}(\Delta 3-51)-E R$ and $10 \mathrm{~T} 1 / 2-\mathrm{MyoD}(\Delta 63-99)-E R$ cells were transiently transfected with either pTK-CAT or p4RTK-CAT and subsequently induced with estradiol for $10.5 \mathrm{hr}$. (A) Enzyme access was analyzed at the -170 PstI site in the myogenin promoter as described in Fig. 3. $(B)$ CAT assays from sister plates represented as the fold activation of CAT activity comparing p4RTK-CAT (containing multimerized MyoD-binding sites) with pTKCAT. (B) BamHI; (R) EcoRI; (N) nuclei; (P) purified DNA. 
MyoD is capable of accessing binding sites within transcriptionally inactive chromatin, and initiating both chromatin remodeling and transcription. MyoD was more effective than myogenin at activating genes within repressed chromatin, in part as a result of a region rich in cysteine and histidine residues and a region in the carboxyl terminus of MyoD. Both of these regions have areas that are highly conserved in the Myf5 protein, and Myf5 has an ability to activate endogenous genes that is comparable to MyoD. These findings suggest a model in which the myogenic bHLH proteins that determine the skeletal muscle lineage, MyoD and Myf5, can remodel chromatin at target genes into an open, or active, conformation, whereas the transcription factors that mediate the expression of muscle genes in the differentiated cell, such as myogenin, are relatively inefficient at activating genes in repressive chromatin and are therefore constrained to act on genes that have been preset in an open, or active, chromatin conformation.

Our data are consistent with a process in which the induction of chromatin reorganization by MyoD is not attributable solely to local nucleosome displacement associated with movement of the RNA Pol II holoenzyme. Chromatin alterations were observed at the $M C K$ and myoD loci at sites 1.2 and $5.2 \mathrm{~kb}$ upstream of transcription initiation, making it unlikely that passage of the transcriptional machinery had displaced nucleosomes in these areas. In addition, chromatin modifications were detected when transcription was inhibited by ATP depletion, indicating that transcriptional elongation is not required for MyoD-initiated chromatin relaxation. We cannot conclude that low levels of ATP are not required for chromatin rearrangement because residual amounts of ATP may be present following treatment with the metabolic inhibitors.

The presence of MyoD-binding sites within target genes is not sufficient for MyoD to initiate chromatin reorganization. MyoD expression did not modify chromatin structure at the $\operatorname{IgH}$ locus despite the presence of multiple $\mathrm{E}$ boxes in the region that are capable of binding MyoD. We cannot at this time determine whether MyoD binds to the $\mathrm{E}$ boxes in the $\mathrm{IgH}$ enhancer without modifying chromatin, or whether the sites cannot be recognized by MyoD because of the special features of the chromatin composition. Sequences flanking the pE5 E box in the $\operatorname{IgH}$ enhancer have been shown to repress transactivation by MyoD (Weintraub et al. 1994) and may function to recruit a factor to this site that prevents MyoD activity. Although the mechanism is not known, our results raise the possibility that this element blocks the capacity for MyoD to alter chromatin structure in the region.

Chromatin modifications occurred at the myogenin promoter in the presence of either metabolic inhibitors or cycloheximide, although more extensive chromatin remodeling was attained when de novo protein synthesis was allowed. It is not likely that this is simply the result of limiting amounts of MyoD, because the amount of myogenin RNA was similar in cycloheximide-treated and -untreated cultures. Furthermore, chromatin modi- fications were similar in the coding region with and without protein synthesis. Thus, our results suggest that the activity of MyoD and ubiquitous factors can cause a limited degree of chromatin relaxation at the myogenin locus, and that newly synthesized proteins are required for full chromatin remodeling to occur. We have not determined whether the partial increase in enzyme access represents incomplete chromatin remodeling at a majority of sites or complete remodeling at only a limited number of sites, as has been suggested for partial enzyme access to $\beta$-globin associated hypersensitive sites with GATA-1- or NFE2-binding site mutations (Boyes and Felsenfeld 1996). The detection of a hypersensitive site at the MEF2 binding site after $48 \mathrm{hr}$ of induction suggests that MEF2, which is induced by MyoD and acts as a coactivator with MyoD, may participate in the completion of chromatin remodeling at the myogenin locus following the initial MyoD-mediated chromatin relaxation. Multistep nucleosomal rearrangement has been described in a number of other systems, such as the induction of PHO5 by Pho4 (Venter et al. 1994) and the cooperation of the SWI/SNF complex with transcription factors to displace nucleosomes (Owen-Hughes et al. 1996). Further work will be necessary to determine whether similar nucleosome remodeling complexes interact with MyoD.

It should be noted that the studies on chromatin remodeling relied on a chimeric protein that incorporated the hormone-binding domain of the estrogen receptor into MyoD and it is possible that this domain may alter the characteristics of the native MyoD protein. For example, p300 has been shown to interact with the ligandbinding domain of the estrogen receptor and related nuclear receptors (Chakravarti et al. 1996; Hanstein et al. 1996; Kamei et al. 1996) and may be artificially incorporated into a DNA-binding complex; however, p300 also interacts with the bHLH region of MyoD (Eckner et al. 1996; Yuan et al. 1996) and may be in the complex in the absence of the estrogen receptor domain. Whereas the potential of the artificial incorporation of a coactivator, such as $\mathrm{p} 300$, into the complex with the chimeric MyoD-ER tempers our interpretation of the ability of the MyoD( $\Delta 3-51)-E R$ to remodel chromatin, for each of the MyoD-ER chimeras tested [MyoD-ER, MyoD( $\Delta 3-51)$ $\mathrm{ER}$, and $\mathrm{MyoD}(\Delta 63-99)-\mathrm{ER}]$ the ability to remodel chromatin was the same as the ability of the non-fusion proteins [MyoD, MyoD( $(\Delta 3-51)$, and $\operatorname{MyoD}(\Delta 63-99)]$ to induce transcription of endogenous genes, suggesting that the the incorporation of the ER domain is not fundamentally altering the activity of the MyoD proteins.

Our analysis of activation of endogenous versus transfected templates revealed that myf-5 and $\mathrm{MyoD}$ were more potent than myogenin in activating endogenous muscle gene expression. Because genetic studies in mice have shown that MyoD and Myf-5 determine the muscle lineage (Braun et al. 1994), whereas myogenin is critical for driving terminal muscle differentiation (Venuti et al. 1995), our data suggests that the ability to access nucleosomal binding sites efficiently and relax chromatin structure is an attribute common to factors involved in 
lineage determination. In contrast to our results, however, Wang et al. (1996) demonstrated that myogenin expressed from the myf-5 locus can rescue the rib-defect phenotype and activate the expression of endogenous muscle genes in myf- 5 null mice, but the levels of gene expression relative to wild-type mice were not determined quantitatively. In our experiments, the different abilities among the myogenic factors to activate muscle gene expression within repressive chromatin were quantitative, rather than qualitative, and the relative differences among the factors diminished when transfected cells were left in differentiation medium for several days (data not shown). Based on our studies, we would predict that myogenin will not completely rescue myogenesis in a myoD and myf-5 double knock-out mouse because of its relative inability to activate genes in repressed chromatin.

Local chromatin structure established during development may subsequently influence gene expression within a lineage by determining the access of other transcription factors to binding sites. In this regard, MyoD and myf- 5 are believed to establish separate lineages during mouse development, which together comprise the muscle compartment (Braun and Arnold 1996). Therefore, if MyoD and myf-5 have slightly different target specificities, then the lineage identity that each establishes can be maintained despite the subsequent expression of shared transcription factors, such as MEF2 and myogenin, which are relatively constrained to act at genes with relaxed chromatin structure. We would predict that other tissue-specific bHLH families, such as the NeuroD family of neurogenic bHLH proteins, will be shown to contain early expressed members that alter chromatin structure at target genes and later expressed members that regulate gene expression within the constraints of a pre-established chromatin structure. In this manner, the combinatorial action of a relatively small number of transcription factors acting both temporally and spatially could generate a high degree of diversity.

The chromatin structure within a lineage may also influence the transcriptional response to agents that antagonize differentiation. When added at the time of MyoD induction, sodium butyrate, TGF- $\beta$, and basicFGF blocked chromatin reorganization and the initiation of myogenin gene transcription. In contrast, TGF- $\beta$ and sodium butyrate did not block myogenin transcription when added after chromatin remodeling had occurred. We conclude that once transcription is initiated and chromatin relaxation is accomplished, then either MyoD or other transcription factors, such as MEF2, can maintain an active state in the presence of myogenic inhibitors. In particular, whereas the myoD family is subject to both auto- and cross-activation (Thayer et al. 1989), our data suggest that active chromatin conformations can allow stable maintenance of myoD family member expression in the presence of inhibitory factors. This would explain the maintenance of myogenic identity in myoblasts following exposure to myogenic inhibitors in cell culture and during development. Together with previous results demonstrating that active chromatin conforma- tions can be propagated to daughter cells (Groudine and Weintraub 1982), the timing of exposure to growth factors relative to gene activation could lock in a particular developmental state, providing a mechanism for the expansion of specific cell populations that represent an intermediate phenotype relative to terminal differentiation.

The ability of MyoD to activate genes within inactive chromatin mapped to amino acids 63-99, a region rich in cysteines and histidines (the $\mathrm{C} / \mathrm{H}$ region), and amino acids 218-269. With the exception of the $\mathrm{C} / \mathrm{H}$ region interacting with the negative regulator I-mf /Chen et al. 1996), neither region had a function identified previously. Both the $\mathrm{C} / \mathrm{H}$ region and the carboxy-terminal region encompass motifs that are highly conserved between MyoD and Myf-5, supporting the notion that the ability to modify chromatin may be a feature common to factors involved in lineage determination. Deletion of either region significantly weakened the ability of MyoD to activate endogenous muscle genes, and deletion of the $\mathrm{C} / \mathrm{H}$ region impaired the induction of chromatin remodeling by MyoD. The effects of the MyoD( $\Delta 63-99)$ deletion and the $\mathrm{MyoD}(\Delta 218-269)$ deletion are not simply attibutable to a reduction in the strength of MyoD as a transcriptional activator, because their activity was comparable to wild-type $\mathrm{MyoD}$ and greater than $\operatorname{MyoD}(\Delta 3-51)$ when assayed on a transfected reporter. Furthermore, our previous work using GAL4/MyoD fusion proteins to map regions of the MyoD protein that enhance transcription from transfected reporters identified an activation domain in the region between amino acids 3 and 51, but showed no activation potential for the $\mathrm{C} / \mathrm{H}$ or carboxy-terminal regions (Weintraub et al. 1991). In fact, deleting either of these two regions increased the activation potential of the GAL4/MyoD fusion protein. We conclude that the $\mathrm{C} / \mathrm{H}$ domain and the carboxy-terminal domain do not function as typical activation domains, but rather mediate an interaction between MyoD and factors that remodel chromatin, increasing the probability that MyoD will initiate chromatin relaxation and activate gene expression. One intriguing possibility is that these domains participate in the recruitment of chromatin remodeling complexes such as the SWI/SNF complex, a member of which has been shown recently to have a muscle-specific isoform (Wong et al. 1996). It will be of interest to identify factors that interact with these regions and to determine whether members of other bHLH families involved in lineage determination contain functionally similar domains that initiate lineagespecific chromatin remodeling.

\section{Materials and methods}

Plasmids

pEMSV-myogenin was a gift of A. Chen (Harvard Medical School, Boston, MA). pMyo1565-CAT was a gift from E. Olsen (Edmondson et al. 1992). pEMSV-MyoD(A3-51)-ER and pEMSV-MyoD( $\Delta 63-99)-E R$ were constructed by inserting the hormone-binding domain of the estrogen receptor into the NarI site of pEMSV-MyoD, as described for the construction of 
pEMSV-MyoD-ER (Hollenberg et al. 1993). Other plasmids are as referenced in the text.

\section{Cell culture}

10T1/2 and 3T3 cells were obtained from the American Type Culture Collection (ATCC). Cells were maintained in Dulbecco's modified Eagle medium (DMEM) supplemented with $10 \%$ or $15 \%$ calf serum (Hyclone), penicillin, and streptomycin. Differentiation medium was DMEM supplemented with $10 \mu \mathrm{g} / \mathrm{ml}$ of insulin and transferrin. Inductive medium was differentiation medium supplemented with $10^{-7} \mathrm{M} \beta$-estradiol.

\section{Transfections}

Transfections were performed by calcium phosphate precipitation as described (Weintraub et al. 1991). In the experiments to determine relative activation efficiency of endogenous versus transfected genes, cells in 6-cm TC dishes (Corning) were transfected for $12 \mathrm{hr}$ with $0.5 \mathrm{mg} \mathrm{pCMV}-\mathrm{LacZ}, 2 \mathrm{mg}$ of CAT reporter, and $5 \mathrm{mg}$ of myogenic factor expression plasmid per 6-cm dish, after which the medium was replaced with fresh growth medium for $2 \mathrm{hr}$, followed by differentiation medium for $24 \mathrm{hr}$. Immunohistochemistry, X-gal staining, CAT assays, and luciferease assays were performed as described previously (Weintraub et al. 1991; Alevizopoulos et al. 1995; Gerber and Tapscott 1996). Stable transformants were generated with pmyoD $(\Delta 3-$ 51)-ER by coelectroporation with SV2-Neo and G418 selection, and with pmyoD $(\Delta 63-99)$-ER by cotransfection with $\mathrm{pY} 3$, a vector containing the hygromycin resistance gene, and hygromycin selection. Clones were picked and analyzed for MyoD immunoreactivity.

\section{Chromatin analysis}

Cells were trypsinized, suspended in DMEM plus $15 \%$ bovine calf serum (BCS), centrifuged at $2000 \mathrm{rpm}$ for $5 \mathrm{~min}$, and washed once in ice-cold reticulocyte suspension buffer (RSB: $10 \mathrm{mM}$ Tris at $\mathrm{pH} 7.4,10 \mathrm{mM} \mathrm{NaCl}, 5 \mathrm{~mm} \mathrm{MgCl}{ }_{2}$ ). Cells were resuspended in ice-cold lysis buffer (RSB plus $0.1 \%$ NP-40) at a concentration of 1.5 million cells per $\mathrm{ml}$ and incubated on ice for $10 \mathrm{~min}$. Nuclei were isolated by centrifugation at 2000 for $5 \mathrm{~min}$ at $4^{\circ} \mathrm{C}$. The pelleted nuclei were washed once in lysis buffer. For DNase analysis, the lysis buffer was removed and the nuclei were resuspended in RSB containing various concentrations of RNasefree DNase I (GIBCO), and incubated at $37^{\circ} \mathrm{C}$ for $10 \mathrm{~min}$. The reaction was stopped with addition of an equal volume of stop buffer $\{0.6 \mathrm{M} \mathrm{NaCl}, 20 \mathrm{~mm}$ Tris base at ph $7.4,10 \mathrm{mM}$ EDTA, $1 \%$ $\mathrm{SDS}$, and $2 \mathrm{mg} / \mathrm{ml}$ proteinase $\mathrm{K}$ ). For MNase analysis, the lysis buffer was removed and nuclei were resuspended in RSB plus $0.1 \mathrm{mM} \mathrm{CaCl}_{2}$ with $50 \mathrm{U} / \mathrm{ml} \mathrm{MNase}$ (Pharmacia) for $0,5,10,20$, or $40 \mathrm{~min}$, and the reaction was stopped with an equal volume of stop buffer. For restriction endonuclease analysis, isolated nuclei were suspended in $200 \mu \mathrm{l}$ of appropriate restriction endonuclease buffer plus 40 units of restriction enzyme lassay enzymel per $10^{6}$ nuclei. The buffer used for digestions with BanI, ClaI, and Ndel was $20 \mathrm{~mm}$ Tris-acetate, $10 \mathrm{~mm}$ magnesium acetate, $50 \mathrm{~mm}$ potassium acetate, $1 \mathrm{~mm}$ DTT at $\mathrm{pH} 7.9$. The buffer used for digestions with PstI, PvuII, and $\mathrm{XbaI}$ was 10 $\mathrm{mm}$ Tris-HCl, $10 \mathrm{~mm} \mathrm{MgCl}_{2}, 50 \mathrm{mM} \mathrm{NaCl}, 1 \mathrm{~mm}$ DTT at $\mathrm{pH} 7.9$. Following $30 \mathrm{~min}$ of incubation at $37^{\circ} \mathrm{C}$, an equal volume of stop buffer was added to each reaction. Samples treated with DNase I, MNase, or restriction endonucleases were incubated overnight at $37^{\circ} \mathrm{C}$ following the addition of stop buffer, and the DNA was purified by phenol-chloroform extraction and ethanol precipitation. The purified DNA was digested with flanking enzymes as indicated in the figure legends, and Southern blotted as described (Otten and Tapscott 1995) For quantitative analysis of endonuclease access, following digestion of the purified DNA with flanking enzymes, $50 \%$ of each sample was digested to completion with the assay enzyme. The percent access of the assay enzyme to sites in the isolated nuclei was obtained by dividing the density of bands from assay enzyme digestion of nuclei $(N)$ with the density of the band generated with digestion of purified DNA (P). Densities for the N/P percentage were obtained using a Molecular Dynamics PhosphorImager.

\section{Acknowledgments}

We dedicate this manuscript to Howard Holtzer and the late Harold Weintraub, who established the basis for this work. We thank Mark Groudine, Dan Gottschling, and Keith Fournier for critical reading of the manuscript. Members of the Tapscott laboratory made important contributions to this work, and Stan Hollenberg provided helpful advice. We also thank Eric Olson and Tom Kadesch for probes to myogenin and IgH. A.N.G. was supported by a predoctoral fellowship from Merck. T.R.K. was supported by a fellowship from the Poncin Foundation. S.J.T. was supported by a Shannon Award from the National Institutes of Health.

The publication costs of this article were defrayed in part by payment of page charges. This article must therefore be hereby marked "advertisement" in accordance with 18 USC section 1734 solely to indicate this fact.

\section{References}

Adolph, E.A., A. Subramaniam, P. Cserjesi, E.N. Olson, and J. Robbins. 1993. Role of myocyte-specific enhancer-binding factor (MEF-2) in transcriptional regulation of the alpha-cardiac myosin heavy chain gene. T. Biol. Chem. 268: 53495352 .

Alevizopoulos, A., Y. Dusserre, M. Tsai-Pflugfelder, T. von der Weid, W. Wahli, and N. Mermod. 1995. A proline-rich TGF$\beta$-responsive transcriptional activator interacts with histone H3. Genes \& Dev. 9: 3051-3066.

Archer, T.K., P. Lefebvre, R.G. Wolford, and G.L. Hager. 1992. Transcription factor loading on the MMTV promoter: A bimodal mechanism for promoter activation. Science 255: 15731576.

Asakura, A., A. Fujisawa-Sehara, T. Komiya, and Y. Nabeshima. 1993. MyoD and myogenin act on the chicken myosin lightchain 1 gene as distinct transcriptional factors. Mol. Cell. Biol. 13: 7153-7162.

Barton, M.C., N. Madani, and B.M. Emerson. 1993. The erythroid protein cGATA-1 functions with a stage-specific factor to activate transcription of chromatin-assembled $\beta$-globin genes. Genes \& Dev. 7: 1796-1809.

Biben, C., B.J. Kirschbaum, I. Garner, and M. Buckingham. 1994. Novel muscle-specific enhancer sequences upstream of the cardiac actin gene. Mol Cell. Biol. 14: 3504-3513.

Black, B.L., J.F. Martin, and E.N. Olson. 1995. The mouse MRF4 promoter is trans-activated directly and indirectly by muscle-specific transcription factors. J. Biol. Chem. 270: 28892892.

Blackwell, T.K. and H. Weintraub. 1990. Differences and similarities in DNA-binding preferences of MyoD and E2A protein complexes revealed by binding site selection. Science 250: 1104-1110.

Boyes, J. and G. Felsenfeld. 1996. Tissue-specific factors additively increases the probability of the all-or-none formation of a hypersensitive site. EMBO T. 15: 2496-2507. 
Braun, T. and H.H. Arnold. 1996. Myf-5 and myoD genes are activated in distinct mesenchymal stem cells and determine different skeletal muscle cell lineages. EMBO J. 15: 310-318.

Braun, T., E. Bober, M.A. Rudnicki, R. Jaenisch, and H.H. Arnold. 1994. MyoD expression marks the onset of skeletal myogenesis in Myf-5 mutant mice. Development 120: 30833092.

Buckingham, M. 1992. Making muscle in mammals. Trends Genet. 8: 144-148.

Catala, F., R. Wanner, P. Barton, A. Cohen, W. Wright, and M. Buckingham. 1995. A skeletal muscle-specific enhancer regulated by factors binding to $\mathrm{E}$ and CArG boxes is present in the promoter of the mouse myosin light-chain $1 \mathrm{~A}$ gene. Mol. Cell. Biol. 15: 4585-4596.

Chakravarti, D., V.J. LaMorte, M.C. Nelson, T. Nakajima, I.G. Schulman, H. Juguilon, M. Montiminy, and R.M. Evans. 1996. Role of CBP/P300 in nuclear receptor signalling. $\mathrm{Na}$. ture 383: 99-103.

Chen, A.C., N. Kraut, M. Groudine, and H. Weintraub. 1996. I-mf, a novel myogenic repressor, interacts with members of the MyoD family. Cell 86: $731-741$.

Cheng, T.C., M.C. Wallace, J.P. Merlie, and E.N. Olson. 1993. Separable regulatory elements governing myogenin transcription in mouse embryogenesis. Science 261: 215-218.

Clark, D.J. and G. Felsenfeld. 1992. A nucleosome core is transferred out of the path of a transcribing polymerase. Cell 71: 11-22.

Cote, J., J. Quinn, J.L. Workman, and C.L. Peterson. 1994. Stimulation of GAL4 derivative binding to nucleosomal DNA by the yeast SWI/SNF complex. Science 265: 53-60.

Eckner, R., T. Yao, E. Oldread, and D.M. Livingston. 1996. Interaction and functional collaboration of p300/CBP and bHLH proteins in muscle and B-cell differentiation. Genes \& Dev. 10: 2478-2490.

Edmondson, D.G. and E.N. Olson. 1993. Helix-loop-helix proteins as regulators of muscle-specific transcription. J. Biol. Chem. 268: 755-758.

Edmondson, D.G., T.C. Cheng, P. Cserjesi, T. Chakraborty, and E.N. Olson. 1992. Analysis of the myogenin promoter reveals an indirect pathway for positive autoregulation mediated by the muscle-specific enhancer factor MEF-2. Mol. Cell. Biol. 12: 3665-3677.

Fascher, K.D., J. Schmitz, and W. Horz. 1993. Structural and functional requirements for the chromatin transition at the PHO5 promoter in Saccharomyces cerevisiae upon PHO5 activation. J. Mol. Biol. 231: $658-667$.

Felsenfeld, G., J. Boyes, J. Chung, D. Clark, and V. Studitsky. 1996. Chromatin structure and gene expression. Proc. Natl. Acad. Sci. 93: 9384-9388.

Gerber, A.N. and S.J. Tapscott. 1996. Tumor cell complementation groups based on myogenic potential: Evidence for inactivation of loci required for basic helix-loop-helix protein activity. Mol. Cell. Biol, 16: 3901-3908.

Granok, H., B.A. Leibovitch, C.D. Shaffer, and S.C.R. Elgin. 1995. Ga-ga over GAGA factor. Curr. Biol. 5: 238-241.

Groudine, M. and H. Weintraub. 1982. Propagation of globin DNase I-hypersensitive sites in absence of factors required for induction: A possible mechanism for determination. Cell 30: 131-139.

Hannon, K., C.K. Smith, K.R. Bales, and R.F. Santerre. 1992. Temporal and quantitative analysis of myogenic regulatory and growth factor gene expression in the developing mouse embryo. Dev. Biol. 151: 137-144.

Hanstein, B., R. Eckner, J. DiRenzo, S. Halachmi, H. Liu, B. Searcy, R. Kurokawa, and M. Brown. 1996. p300 is a component of an estrogen receptor coactivator complex. Proc. Natl.
Acad. Sci. 93: $11540-11545$

Hasty, P., A. Bradley, J.H. Morris, D.G. Edmondson, J.M. Venuti, E.N. Olson, and W.H. Klein. 1993. Muscle deficiency and neonatal death in mice with a targeted mutation in the myogenin gene [see comments]. Nature 364: 501-506.

Hollenberg, S.M., P.F. Cheng, and H. Weintraub. 1993. Use of a conditional MyoD transcription factor in studies of MyoD trans-activation and muscle determination. Proc. Natl. Acad. Sci. 90: 8028-8032.

Jaynes, J.B., J.E. Johnson, J.N. Buskin, C.L. Gartside, and S.D. Hauschka. 1988. The muscle creatine kinase gene is regulated by multiple upstream elements, including a musclespecific enhancer. Mol. Cell. Biol. 8: 62-70.

Jeong, S. and A. Stein. 1994. Micrococcal nuclease digestion of nuclei reveals extended nucleosome ladders having anomalous DNA lengths for chromatin assembled on non-replicating plasmids in transfected cells. Nucleic Acids Res. 22: $370-375$.

Jiang, Y., M. Yan, and J.D. Gralla. 1996. A three-step pathway of transcription initiation leading to promoter clearance at an activation RNA polymerase II promoter. Mol. Cell. Biol.16: 1614-1621.

Johnston, L.A., S.J. Tapscott, and H. Eisen. 1992. Sodium butyrate inhibits myogenesis by interfering with the transcriptional activation function of MyoD and myogenin. Mol. Cell. Biol. 12: 5123-5130.

Kamei, Y., L. Xu, T. Heinzel, J. Torchia, R. Kurokawa, B. Gloss, S. Lin, R.A. Heyman, D.W. Rose, C.K. Glass, and M.G. Rosenfeld. 1996. A CBP integrator complex mediates transcriptional activation and AP-1 inhibition by nuclear receptors. Cell 85: 403-414.

$\mathrm{Li}, \mathrm{H}$. and Y. Capetanaki. 1994. An E box in the desmin promoter cooperates with the E box and MEF-2 sites of a distal enhancer to direct muscle-specific transcription. $E M B O T$. 13: $3580-3589$.

Li, L., J. Zhou, G. James, R. Heller-Harrison, M.P. Czech, and E.N. Olson. 1992. FGF inactivates myogenic helix-loophelix proteins through phosphorylation of a conserved protein kinase $\mathrm{C}$ site in their DNA-binding domains. Cell 71: 1181-1194.

Loo, S. and J. Rine. 1994. Silencers and domains of generalized repression. Science 264: 1768-1771.

Lorico, A., G. Rappa, S. Srimatkandada, C.V. Catapano, D.J. Fernandes, J.F. Germino, and A.C. Sartorelli. 1995. Increased rate of adenosine triphosphate-dependent etoposide (VP-16) efflux in a murine leukemia cell line overexpressing the multidrug resistance-associated protein (MRP) gene. Cancer Res. 55: 4352-4360.

Malik, S., C.F. Huang, and J. Schmidt. 1995. The role of the CANNTG promoter element ( $\mathrm{E}$ box) and the myocyte-enhancer-binding-factor-2 (MEF-2) site in the transcriptional regulation of the chick myogenin gene. Eur. I. Biochem. 230: 88-96.

Martin, J.F., L. Li, and E.N. Olson. 1992. Repression of myogenin function by TGF-beta 1 is targeted at the basic helixloop-helix motif and is independent of E2A products. J. Biol. Chem. 267: 10956-10960.

McGhee, J.D., W.I. Wood, M. Engel, and G. Felsenfeld. 1981. A 200 base pair region at the $5^{\prime}$ end of the chicken adult betaglobin gene is accessible to nuclease digestion. Cell 27: 4555.

Molkentin, J.D., B.L. Black, J.F. Martin, and E.N. Olson. 1995. Cooperative activation of muscle gene expression by MEF2 and myogenic bHLH proteins. Cell 83: 1125-1136.

Morse, R.H. 1993. Nucleosome disruption by transcription factor binding in yeast. Science 262: 1563-1566. 
Nabeshima, Y., K. Hanaoka, M. Hayasaka, E. Esumi, S. Li, and I. Nonaka. 1993. Myogenin gene disruption results in perinatal lethality because of severe muscle defect. Nature 364: 532-535.

Naidu, P.S., D.C. Ludolph, R.Q. To, T.J. Hinterberger, and S.F. Konieczny. 1995. Myogenin and MEF2 function synergistically to activate the MRF4 promoter during myogenesis. Mol. Cell. Biol. 15: 2707-2718.

Otten, A.D. and S.J. Tapscott. 1995. Triplet repeat expansion in myotonic dystrophy alters the adjacent chromatin structure. Proc. Natl. Acad. Sci. 92: 5465-5469.

Owen-Hughes, T., R.T. Utley, J. Cote, C.L. Peterson, and J.L. Workman. 1996. Persistent site-specific remodeling of a nucleosome array by transient action of the SWI/SNF complex. Science 273: 513-516.

Philipsen, S., S. Pruzina, and F. Grosveld. 1993. The minimal requirements for activity in transgenic mice of hypersensitive site 3 of the beta globin locus control region. EMBO J. 12: 1077-1085.

Pieper, R., R.L. Slobbe, F.C.S. Ramaekers, H.T. Cuypers, and H. Bloemendal. 1987. Upstream regions of the hamster desmin and vimentin genes regulate expression during in vitro myogenesis. EMBO J. 6: 3611-3618.

Reeves, R., C.M. Gorman, and B. Howard. 1985. Minichromosome assembly of non-integrated plasmid DNA tranfected into mammalian cells. Nucleic Acids Res. 13: 3599-3615.

Reitman, M. and G. Felsenfeld. 1990. Developmental regulation of topoisomerase II sites and DNase I-hypersensitive sites in the chicken beta-globin locus. Mol. Cell. Biol. 10: 2774-2786.

Rudnicki, M.A. and R. Jaenisch. 1995. The MyoD family of transcription factors and skeletal myogenesis. BioEssays 17: 203-209.

Rudnicki, M.A., P.N. Schnegelsberg, R.H. Stead, T. Braun, H.H. Arnold, and R. Jaenisch. 1993. MyoD or Myf-5 is required for the formation of skeletal muscle. Cell 75: 1351-1359.

Stalder, J., A. Larsen, J.D. Engel, M. Dolan, M. Groudine, and H. Weintraub. 1980. Tissue-specific DNA cleavages in the globin chromatin domain introduced by DNase I. Cell 20: 451460.

Stamatoyannopoulos, J.A., A. Goodwin, T. Joyce, and C.H. Lowrey. 1995. NF-E2 and GATA binding motifs are required for the formation of DNase I hypersensitive site 4 of the human beta-globin locus control region. EMBO I. 14: 106-116.

Svaren, J., J. Schmitz, and W. Horz. 1994. The transactivation domain of Pho4 is required for nucleosome disruption at the PHO5 promoter. EMBO I. 13: 4856-4862.

Tapscott, S.J., R.L. Davis, M.J. Thayer, P.F. Cheng, H. Weintraub, and A.B. Lassar. 1988. MyoDl: A nuclear phosphoprotein requiring a Myc homology region to convert fibroblasts to myoblasts. Science 242: $405-411$.

Tapscott, S.J., A.B. Lassar, and H. Weintraub. 1992. A novel myoblast enhancer element mediates MyoD transcription. Mol. Cell. Biol. 12: 4994-5003.

Thayer, M.J., S.J. Tapscott, R.L. Davis, W.E. Wright, A.B. Lassar, and H. Weintraub. 1989. Positive autoregulation of the myogenic determination gene MyoD1. Cell 58: 241-248.

Tsukiyama, T. and C. Wu. 1995. Purification and properties of an ATP-dependent nucleosome remodeling factor. Cell 83: $1011-1020$.

Tsukiyama, T., C. Daniel, J. Tamkun, and C. Wu. 1995. ISWI, a member of the SWI2/SNF2 ATPase family, encodes the 140 $\mathrm{kDA}$ subunit of the nucleosome remodeling factor. Cell 83: 1021-1026.

Venter, U., J. Svaren, J. Schmitz, A. Schmid, and W. Horz. 1994. A nucleosome precludes binding of the transcription factor Pho4 in vivo to a critical target site in the PHO5 promoter.
EMBO I. 13: 4848-4855.

Venuti, J.M., J.H. Morris, J.L. Vivian, E.N. Olson, and W.H. Klein. 1995. Myogenin is required for late but not early aspects of myogenesis during mouse development. J. Cell. Biol. 128: $563-576$.

Wang, Y., P.N. Schnegelsberg, J. Dausman, and R. Jaenisch. 1996. Functional redundancy of the muscle-specific transcription factors Myf5 and myogenin. Nature 379: $823-825$.

Weintraub, H. 1985. Assembly and propagation of repressed and depressed chromosomal states. Cell 42: 705-711.

- 1993. The MyoD family and myogenesis: Redundancy, networks, and thresholds. Cell 75: $1241-1244$.

Weintraub, H. and M. Groudine. 1976. Chromosomal subunits in active genes have an altered conformation. Science 193: 848-856.

Weintraub, H., S.J. Tapscott, R.L. Davis, M.J. Thayer, M.A. Adam, A.B. Lassar, and A.D. Miller. 1989. Activation of muscle-specific genes in pigment, nerve, fat, liver, and fibroblast cell lines by forced expression of MyoD. Proc. Natl. Acad. Sci. 86: $5434-5438$.

Weintraub, H., V.J. Dwarki, I. Verma, R. Davis, S. Hollenberg, L. Snider, A. Lassar, and S.J. Tapscott. 1991. Muscle-specific transcriptional activation by MyoD. Genes \& Dev. 5: $1377-$ 1386.

Weintraub, H., T. Genetta, and T. Kadesch. 1994. Tissue-specific gene activation by MyoD: Determination of specificity by cis-acting repression elements. Genes \& Dev. 8: 22032211.

Wolffe, A.P. 1992. New insights into chromatin function in transcriptional control. FASEB J. 6: 3354 -3361.

Wong, W., Y. Xue, S. Zhou, A. Kuo, B.R. Cairns, and G.R. Grabtree. 1996. Diversity and specialization of mammalian SWI/ SNF complexes. Genes \& Dev. 10: 2117-2130.

Yee, S.P. and P.W. Rigby. 1993. The regulation of myogenin gene expression during the embryonic development of the mouse. Genes \& Dev. 7: 1277-1289.

Yuan, W., G. Condorelli, M. Caruso, A. Felsani, and A. Giordano. 1996. Human p300 protein is a coactivator for the transcription factor MyoD. J. Biol. Chem. 271: 9009-9013. 


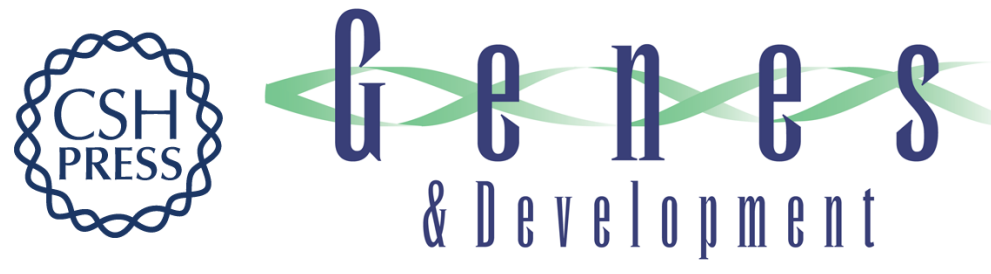

\section{Two domains of MyoD mediate transcriptional activation of genes in repressive chromatin: a mechanism for lineage determination in myogenesis.}

A N Gerber, T R Klesert, D A Bergstrom, et al.

Genes Dev. 1997, 11:

Access the most recent version at doi:10.1101/gad.11.4.436

References This article cites 75 articles, 40 of which can be accessed free at: http://genesdev.cshlp.org/content/11/4/436.full.html\#ref-list-1

License

Email Alerting Service

Receive free email alerts when new articles cite this article - sign up in the box at the top right corner of the article or click here.

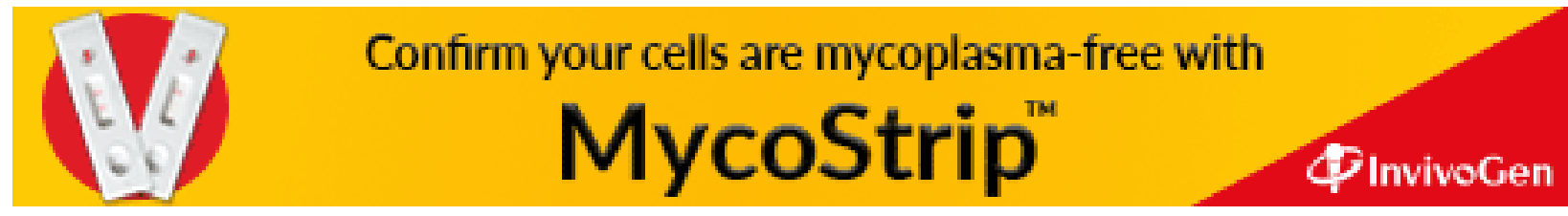

